\title{
Prevalence of Swimming Puppy Syndrome in 2,443 Puppies during the Years 2006-2012 in Thailand
}

\author{
Korakot Nganvongpanit ${ }^{1,2}$ and Terdsak Yano ${ }^{3}$ \\ ${ }^{1}$ Animal Bone and Joint Research Laboratory, Department of Veterinary Biosciences and Public Health, Faculty of Veterinary Medicine, \\ Chiang Mai University, Chiang Mai 50100, Thailand \\ ${ }^{2}$ Materials Science Research Center, Faculty of Science, Chiang Mai University, Chiang Mai 50200, Thailand \\ ${ }^{3}$ Department of Food Animals, Faculty of Veterinary Medicine, Chiang Mai University, Chiang Mai 50100, Thailand
}

Correspondence should be addressed to Korakot Nganvongpanit; korakot.n@cmu.ac.th

Received 12 March 2013; Revised 11 May 2013; Accepted 14 May 2013

Academic Editor: Remo Lobetti

Copyright (C) 2013 K. Nganvongpanit and T. Yano. This is an open access article distributed under the Creative Commons Attribution License, which permits unrestricted use, distribution, and reproduction in any medium, provided the original work is properly cited.

\begin{abstract}
The purpose of this study was to report on the prevalence of swimming puppy syndrome (SPS) and investigate predisposing factors. Data were recorded from 2,443 puppies (1,183 males and 1,260 females) in Thailand, October 2006-September 2012, including breed, sex, number of puppies per litter, type of nest floor, number of affected limbs, and occurrence of pectus excavatum. Fifty-two puppies $(2.13 \%)$ were diagnosed with SPS. The breed most frequently affected was English Bulldog (8.33\%). There was no significant difference $(P>0.05)$ between presence and absence of disease based on sex, breed, and nest floor type. The number of puppies per litter was associated with SPS; puppies from smaller litters $(1.92 \pm 1.12)$ had a higher prevalence of the disease $(P<0.01)$ than puppies from larger litters $(3.64 \pm 2.24)$. Moreover, $15.38 \%$ of puppies with affected limbs showed signs of pectus excavatum (8/52); this clinical sign was more prevalent $(P<0.01)$ in puppies with all four limbs affected with SPS.
\end{abstract}

\section{Introduction}

Swimming puppy syndrome-also known as swimmer syndrome, flat pup syndrome, splay leg (paraparesis), splay weak (tetraparesis), and myofibrillar hypoplasia-is one of the musculoskeletal disorders in puppies [1]. In the initial weeks of life, newborn puppies seem normal: they gain weight quickly, suck well, and appear to be completely healthy. Signs begin to appear when the puppy learns to walk (2nd-3rd week), with spreadout legs like a swimmer [1]. In some cases, there are additional complications, because such puppies tend to lie on their bellies most of the time. The center of gravity is shifted to the chest, while the soft ribs cannot maintain their correct shape; thus the chest, under the pressure of body weight, splays on both sides, and the thorax becomes flat (funnel chest) [2-4]. Some puppies show snake-like or walrus-swimming movements, crawling on their bellies with limbs extended and exorotated. Sterna concave, dorsoventral flattening of the chest, or pectus excavatum will present when forelimbs are affected $[2,3]$. In cases of pectus excavatum, puppies show respiratory insufficiency, with dyspnoea, mouth continuously open, and bluish mucous membranes $[3,4]$. The differential diagnosis of this disease includes encephalomeningitis, canine distemper, toxoplasmosis, neosporosis, myopathies, and spina bifida [4, 5]. The treatment success rate is dependent on the time of diagnosis and treatment $[4,5]$. Usually puppies with this disease recover well after early diagnosis and treatment such as limb realignment, bandages, and physical rehabilitation $[4,5]$.

However, little is known about the prevalence of swimming puppy syndrome, other than from observational experience and a limited amount of information available on the internet (based on a search of PubMed and Scopus databases). Also, several of these publications were in the format of case reports in which only a few puppies showed signs of this disease [1-6]. From the existing information [5], it can be concluded that some of the predisposing causes 
of the disease are small breeds (Dachshund and Yorkshire Terrier) and also breeds with a large thorax and short limbs (Pekingese, Basset Hound, French, and English Bulldogs). Other predisposing causes [4] include puppies of normal size at birth but with faster growth than the rest of the litter and, in particular, a low number of puppies per litter.

In the present study, the number of cases of swimming puppy syndrome was recorded by breed, together with other factors; statistical analysis was used to study the prevalence, incidence, and risk factors of this disease.

\section{Materials and Methods}

2.1. Animals. In this retrospective study of clinical records (Table 1) of 2,443 puppies (1,183 males and 1,260 females) that were 3 months old or younger were reviewed. The puppies had undergone treatment for various reasons at 19 animal clinics/hospitals in Thailand (Figure 1) from October 2006 to September 2012.

The data collected included breed, age, weight, sex, number of puppies per litter, and floor condition on which the puppies were fostered. Moreover, the findings of the clinical examination of all affected puppies were reviewed, including affected limbs and the occurrence of pectus excavatum.

In case there was missing data, the authors called the pet owner to ask for the necessary information. If the pet owner was unable to supply the missing data, or when information about other puppies in the same litter could not be obtained, the puppy was excluded from the study.

2.2. Statistical Analysis. Demographic data of the samples were described by descriptive statistics. Sex, breed size, floor conditions, and number of puppies per litter were assumed to be the associated risk factors for swimmer puppy syndrome and were investigated to determine the correlation between these factors and swimming puppy syndrome. The correlation between affected limb(s) and the occurrence of pectus excavatum was analyzed using the $\mathrm{R}$ statistical software program. For statistical analysis, dogs were categorized according to weight into three groups: large ( $>25 \mathrm{~kg}$ ), medium $(10-25)$, and small $(<10 \mathrm{~kg})$ breeds. The epi2x2 function in the epibasix package was used to examine the correlation between sex and the occurrence of the disease. A chi-squared test was used to evaluate the correlation between breed size, type of floor, and occurrence of the disease. Fisher's exact test was used to determine the correlation between affected limbs and the occurrence of pectus excavatum. Finally, the mean number of puppies per litter and the presence of diseased and nondiseased animals were analyzed by a $t$-test. The significance level was set at $P<0.05$.

\section{Results}

The present study found that the disease started to present beginning at week $3 \pm 1$, but the owner brought puppy to the visiting veterinarian at week $7 \pm 3$.

3.1. Breed. A total of 2,443 puppies (1,183 males and 1,260 females) were included in this study. Twenty-two breeds of

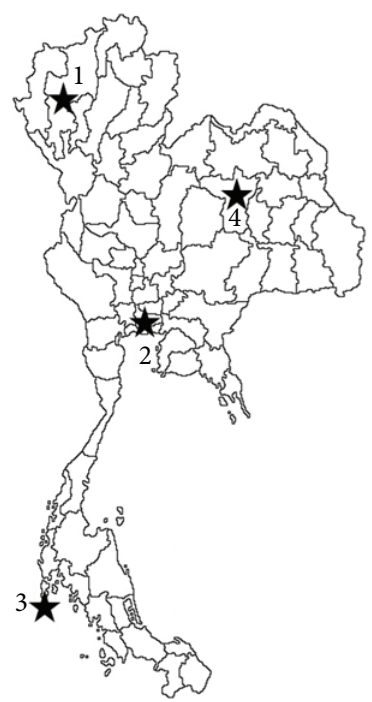

Geographic distribution of cases

1: Chiang Mai province; 1892 puppies from 12 clinics/hospitals

2: Bangkok province; 340 puppies from 5 clinics/hospitals

3: Phuket province; 172 puppies from 2 clinics/hospitals

4: Khon Kaen province; 37 puppies from 2 clinics/hospitals

FIGURE 1: Geographic distribution of cases and clinics/hospitals included in the study in Thai.

puppies were recorded in the clinical notes and of these, swimming puppy syndrome was recorded in 15 breeds. Comparing within breed, English Bulldog was found to have the highest percentage of diseased puppies, $8.33 \%(4 / 48)$; second was French Bulldog, 7.54\% (4/53), and third was Pekingese, $6.89 \%(4 / 58)$. The other breeds were found to have a mean prevalence of $2.65 \%$ (range $0.78-5.55 \%$ ), as shown in Table 2.

Comparison of all affected breeds revealed that Golden Retriever had the highest percentage of affected puppies (15.38\%), followed by Siberian Husky (13.46\%) and Labrador Retriever (9.62\%). The lowest prevalence was found in Dachshunds (1.92\%), followed by five other breeds, including Chihuahua, Pomeranian, Pug, Yorkshire Terrier, and Thai Bangkaew, all with the same percentage (3.85\%).

Affected puppies were compared within the same sized groups; medium-size puppies were found to have the highest number of affected animals (3.32\%). Affected percentages of large and small sizes were $2.44 \%$ and $1.54 \%$, respectively. Comparatively, the number of affected puppies in terms of breed size was not significantly different $(P=0.07)$.

3.2. Sex. As shown in Table 2, of the 52 number of puppies affected by swimming puppy syndrome, $56 \%$ was males $(n=$ $29)$, and $44 \%$ was females $(n=23)$. The prevalence of swimming puppy syndrome was not significantly different between male and female dogs $(P=0.484)$ (Table 3 ).

3.3. Number of Puppies per Litter. This study found a significant decrease $(P<0.01)$ in the number of puppies per litter in the affected group $(1.92 \pm 1.12)$ compared to clinical unaffected dogs $(3.64 \pm 2.24)$ (Table 4$)$. The number 
TABLE 1: Number of puppies in each breed included in the study.

\begin{tabular}{|c|c|c|c|c|c|}
\hline Breed & Total & Male & Female & Number of litters & Number of puppies/litter (mean \pm SD) \\
\hline \multicolumn{6}{|l|}{ Small breed $(<10 \mathrm{~kg})$} \\
\hline Chihuahua & 256 & 125 & 131 & 111 & $2 \pm 1$ \\
\hline Dachshund & 18 & 8 & 10 & 5 & $4 \pm 2$ \\
\hline Jack Russell Terrier* & 19 & 15 & 4 & 6 & $3 \pm 1$ \\
\hline Pekingese & 58 & 27 & 31 & 22 & $3 \pm 1$ \\
\hline Pomeranian & 293 & 131 & 162 & 130 & $2 \pm 1$ \\
\hline Poodle & 82 & 45 & 37 & 26 & $3 \pm 1$ \\
\hline Pug & 77 & 31 & 46 & 23 & $3 \pm 1$ \\
\hline Shih Tzu & 265 & 123 & 142 & 76 & $3 \pm 1$ \\
\hline Yorkshire Terrier & 165 & 74 & 91 & 79 & $2 \pm 1$ \\
\hline \multicolumn{6}{|l|}{ Medium breed $(10-25 \mathrm{~kg})$} \\
\hline Beagle $^{*}$ & 60 & 36 & 24 & 13 & $5 \pm 2$ \\
\hline Bulldog (English) & 48 & 25 & 23 & 14 & $3 \pm 2$ \\
\hline French Bulldog & 53 & 23 & 30 & 14 & $4 \pm 1$ \\
\hline Crossbreed & 122 & 48 & 74 & 21 & $6 \pm 4$ \\
\hline Shetland Sheepdog* & 11 & 5 & 6 & 2 & $6 \pm 1$ \\
\hline Thai Bangkaew & 85 & 49 & 36 & 13 & $7 \pm 2$ \\
\hline Thai Ridgeback* & 13 & 5 & 8 & 2 & $7 \pm 2$ \\
\hline \multicolumn{6}{|l|}{ Large breed $(25-40 \mathrm{~kg})$} \\
\hline American Pit Bull Terrier* & 71 & 32 & 39 & 9 & $8 \pm 2$ \\
\hline German Shepherd* & 76 & 42 & 34 & 11 & $7 \pm 2$ \\
\hline Golden Retriever & 217 & 103 & 114 & 36 & $6 \pm 3$ \\
\hline Labrador Retriever & 213 & 115 & 98 & 36 & $6 \pm 2$ \\
\hline Rottweiler* & 109 & 48 & 61 & 16 & $7 \pm 3$ \\
\hline Siberian Husky & 132 & 73 & 59 & 28 & $5 \pm 2$ \\
\hline Total & 2,443 & 1,183 & 1,260 & $=$ & - \\
\hline
\end{tabular}

${ }^{*}$ Breed was not affected with swimming puppy syndrome.

of puppies per litter in healthy small breeds was $3 \pm 1$ dogs, while in affected puppies it was $1 \pm 1$ dogs. In medium breeds, there were $5 \pm 3$ healthy puppies per litter and $2 \pm 1$ affected puppies per litter. Large breeds showed a similar result, with $6 \pm 3$ healthy puppies per litter versus $3 \pm 1$ affected puppies per litter (Table 5).

3.4. Nest Floor. Swimming puppy syndrome was found to be the highest among puppies raised on concrete floors, followed by tile and wood floors, respectively (Table 6). The percentages of the disease present in animals raised on tile; wood and concrete floors were similar: $2.25 \%, 2.64 \%$ and $1.28 \%$, respectively. However, no significant difference $(P=$ 0.224 ) was established in the prevalence of swimming puppy syndrome between the different floor types.

3.5. Pectus Excavatum. Eight puppies with swimming puppy syndrome had pectus excavatum. Puppies affected in all limbs with swimming puppy syndrome showed a significantly higher $(P<0.01)$ prevalence of pectus excavatum $(87.5 \%)$. When only the forelimbs were affected, $20 \%$ showed signs of pectus excavatum; no signs of pectus excavatum were found when only the hindlimb was affected (Table 7).

\section{Discussion}

Despite numerous investigations, the etiology and pathogenesis of swimming puppy syndrome are poorly understood $[1,4,5]$. Moreover, previous publications have reported that swimming puppy syndrome is an uncommon developmental abnormality observed in puppies $[5,6]$. However, the present study established a prevalence (52) of $2.1 \%$ of 2,443 puppies. According to previous investigations [5-9], the etiopathogenesis of this disease is unclear; the authors propose that nutritional, neurological, hereditary, and orthopaedic causes are possible underlying factors. The results from the present study further clarify some of the unclear underlying causes of this disease.

From our observations, body weight has a significant effect on the likelihood of disease presentation. However, we did not weigh all puppies (diseased and nondiseased) at all ages to conduct a thorough statistical analysis. Another limitation of this study is that puppies were not brought to a clinic/hospital immediately upon presenting the disease. In most cases, the owner delayed bringing the pet to a clinic/hospital until week $7 \pm 3$ of age, while the disease typically presents at week $3 \pm 1$. For this reason, puppies 
TABLE 2: Number of puppies in different breeds affected with swimming puppy syndrome.

\begin{tabular}{|c|c|c|c|c|c|c|c|}
\hline & \multicolumn{3}{|c|}{ Healthy puppies } & \multicolumn{3}{|c|}{ Swimming puppy syndrome } & \multirow{2}{*}{$\%{ }^{* *}$} \\
\hline & Male & Female & Total & Male & Female & Total $\left(\%{ }^{*}\right)$ & \\
\hline \multicolumn{8}{|l|}{ Small breed $(<10 \mathrm{~kg})$} \\
\hline Chihuahua & 125 & 131 & 256 & 1 & 1 & $2(0.78)$ & 3.85 \\
\hline Dachshund & 8 & 10 & 18 & 1 & - & $1(5.55)$ & 1.92 \\
\hline Pekingese & 27 & 31 & 58 & 1 & 3 & $4(6.89)$ & 7.69 \\
\hline Pomeranian & 131 & 162 & 293 & 1 & 1 & $2(0.68)$ & 3.85 \\
\hline Poodle & 45 & 37 & 82 & 2 & 1 & $3(3.65)$ & 5.77 \\
\hline Pug & 31 & 46 & 77 & - & 2 & $2(2.59)$ & 3.85 \\
\hline Shih Tzu & 123 & 142 & 265 & 1 & 2 & $3(1.17)$ & 5.77 \\
\hline Yorkshire Terrier & 74 & 91 & 165 & 1 & 1 & $2(1.21)$ & 3.85 \\
\hline \multicolumn{8}{|c|}{ Medium breed (10-25 kg) } \\
\hline Bulldog (English) & 25 & 23 & 48 & 2 & 2 & $4(8.33)$ & 7.69 \\
\hline French Bulldog & 23 & 30 & 53 & 1 & 3 & $4(7.54)$ & 7.69 \\
\hline Crossbreed & 48 & 74 & 122 & 3 & - & $3(2.45)$ & 5.77 \\
\hline Thai Bangkaew & 49 & 36 & 85 & 2 & 1 & $2(2.35)$ & 3.85 \\
\hline \multicolumn{8}{|l|}{ Large breed (25-40 kg) } \\
\hline Golden Retriever & 103 & 114 & 217 & 6 & 2 & $8(3.68)$ & 15.38 \\
\hline Labrador Retriever & 115 & 98 & 213 & 3 & 2 & $5(2.34)$ & 9.62 \\
\hline Siberian Husky & 73 & 59 & 132 & 4 & 3 & $7(5.30)$ & 13.46 \\
\hline Total & 1,000 & 1,084 & 2,084 & 29 & 23 & 52 & 100 \\
\hline
\end{tabular}

* Percentage of affected puppies compared within breeds.

** Percentage of affected puppies compared between breeds.

TABLE 3: Factor of sex on expression of disease.

\begin{tabular}{lccc}
\hline Sex & Total & $\begin{array}{c}\text { Disease present } \\
\text { (cases) }\end{array}$ & $\begin{array}{c}\text { Disease absent } \\
\text { (controls) }\end{array}$ \\
\hline Male & 1,184 & $29(2.45 \%)$ & $1,155(97.55 \%)$ \\
Female & 1,259 & $23(1.83 \%)$ & $1,236(98.17 \%)$ \\
\hline
\end{tabular}

Pearson's chi-squared statistic (includes Yates' continuity correction) $=0.423$; $P$ value using Fisher's exact test $(1$ degree of freedom $)=0.484$; estimate of odds ratio $=1.248 ; 95 \%$ confidence limits for true odds ratio $=[0.72,2.166]$; estimate of risk difference $\left(p_{1}-p_{2}\right)$ in case-control studies $=0.055 ; 95 \%$ confidence limits for risk difference $=[0.006,0.105]$.

TABLE 4: Number of puppies per litter with presence or absence of disease.

\begin{tabular}{lcc}
\hline Data & $\begin{array}{c}\text { Disease present } \\
\text { (cases) }\end{array}$ & $\begin{array}{c}\text { Disease absent } \\
\text { (controls) }\end{array}$ \\
\hline $\begin{array}{l}\text { Number of samples } \\
\text { Mean number of puppies per }\end{array}$ & 52 & 641 \\
litter & 1.92 & 3.65 \\
Standard deviation & 1.12 & 2.24 \\
\hline
\end{tabular}

$t=9.6906$; degrees of freedom $=88.859 ; P<0.001$.

could not be weighed at a young enough age to determine whether weight was one of the primary risk factors of this disease. However, based on veterinarians' observations, more than $90 \%$ of the affected puppies were overweight and were typically larger than puppies of the same breed at the same age. The primary focus of the present study was on the number of puppies per litter and its effect on presentation of the disease. We also documented that a lower number of puppies per litter resulted in higher body weight of puppies. This study found that a significantly $(P<0.01)$ lower number of puppies per litter were observed in the case of affected puppies $(1.92 \pm 1.12)$ compared to unaffected puppies (3.64 \pm 2.24). Therefore, the statements as mentioned above can conclud that lower number of puppies per litter might be associated with higher body weight of the puppies, but this is not examined.

The results of this study indicate the possibility that hereditary or genetic factors are not the underlying cause of this disease, since out of 52 diseased puppies in this study only 2 puppies (Siberian Husky) were from the same litter. Also, their parents had never given birth to puppies with this syndrome before (in 3 previous litters). Information from other owners also indicated that the puppies affected with the disease were the first that had been born to a particular set of parents. For this reason, we believe that the disease is not genetically related. However, to fulfill the data and elucidate the possible genetic basis of swimming puppy syndrome, our group is conducting a molecular genetics study of candidate genes for this disease; the results are to be published in the near future.

In the case of pigs, splay leg has been proven to be a hereditary disorder $[10,11]$. Maak and others [11] pinpointed the candidate genes for splay leg in piglets using DNA microarray data, comparing the genome-wide gene expression of three hindlimb muscles between affected and healthy piglets. They found 63 transcripts with differences in two muscle groups and 5 gene differences in three muscle groups. Based on 
TABLE 5: Number of puppies per litter in normal and affected groups.

\begin{tabular}{|c|c|c|c|}
\hline \multirow[b]{2}{*}{ Breed } & \multicolumn{2}{|c|}{ Number of puppies per litter } & \multirow[b]{2}{*}{$P$ value } \\
\hline & $\begin{array}{c}\text { Disease } \\
\text { absent }\end{array}$ & $\begin{array}{l}\text { Disease } \\
\text { present }\end{array}$ & \\
\hline \multicolumn{4}{|l|}{ Small breed } \\
\hline Chihuahua & $2 \pm 1$ & $1 \pm 0$ & 0.000 \\
\hline Dachshund & $4 \pm 2$ & - & - \\
\hline $\begin{array}{l}\text { Jack Russell } \\
\text { Terrier }\end{array}$ & $3 \pm 1$ & - & - \\
\hline Pekingese & $3 \pm 1$ & $1 \pm 1$ & 0.001 \\
\hline Pomeranian & $2 \pm 1$ & $2 \pm 0$ & 0.001 \\
\hline Poodle & $3 \pm 1$ & $1 \pm 0$ & 0.000 \\
\hline Pug & $3 \pm 1$ & $2 \pm 1$ & 0.001 \\
\hline Shih Tzu & $3 \pm 1$ & $1 \pm 1$ & 0.006 \\
\hline $\begin{array}{l}\text { Yorkshire } \\
\text { Terrier }\end{array}$ & $2 \pm 1$ & $1 \pm 0$ & 0.000 \\
\hline Mean \pm SD & $3 \pm 1$ & $1 \pm 1$ & \\
\hline \multicolumn{4}{|l|}{ Medium breed } \\
\hline Beagle & $5 \pm 4$ & - & - \\
\hline $\begin{array}{l}\text { Bulldog } \\
\text { (English) }\end{array}$ & $3 \pm 2$ & $2 \pm 1$ & 0.002 \\
\hline French Bulldog & $4 \pm 1$ & $2 \pm 1$ & 0.008 \\
\hline Crossbreed & $6 \pm 4$ & $1 \pm 1$ & 0.000 \\
\hline $\begin{array}{l}\text { Shetland } \\
\text { Sheepdog }\end{array}$ & $6 \pm 1$ & - & - \\
\hline Thai Bangkaew & $7 \pm 2$ & $4 \pm 1$ & 0.005 \\
\hline Thai Ridgeback & $7 \pm 2$ & - & - \\
\hline Mean \pm SD & $5 \pm 3$ & $2 \pm 1$ & \\
\hline \multicolumn{4}{|l|}{ Large breed } \\
\hline $\begin{array}{l}\text { American pit } \\
\text { Bull Terrier }\end{array}$ & $8 \pm 2$ & - & - \\
\hline $\begin{array}{l}\text { German } \\
\text { Shepherd }\end{array}$ & $7 \pm 2$ & - & - \\
\hline $\begin{array}{l}\text { Golden } \\
\text { Retriever }\end{array}$ & $6 \pm 3$ & $2 \pm 1$ & 0.000 \\
\hline $\begin{array}{l}\text { Labrador } \\
\text { Retriever }\end{array}$ & $6 \pm 2$ & $3 \pm 1$ & 0.000 \\
\hline Rottweiler & $7 \pm 3$ & - & - \\
\hline Siberian Husky & $5 \pm 2$ & $3 \pm 2$ & 0.011 \\
\hline Mean \pm SD & $6 \pm 3$ & $3 \pm 1$ & \\
\hline
\end{tabular}

their study results, they concluded that certain genes were associated with splay leg in piglets and that future studies of the genetic mechanism needed to be performed in order to achieve a better understanding of the pathogenesis of this disease.

The present study found that the disease started to present beginning at week $3 \pm 1$, when normal puppies are learning to stand and walk, that is, after 10-14 days of age $[8,12]$. Previous reports also found that the disease started in the 2 nd to 4 th week $[5,13]$. However, in this study, owners typically did not bring their puppies to a clinic or hospital when the disease first presented, but instead waited until puppies were $7 \pm 3$
TABLE 6: Number of litters on different floor types.

\begin{tabular}{|c|c|c|c|c|}
\hline & \multicolumn{3}{|c|}{ Floor type } & \multirow{2}{*}{ Tota } \\
\hline & Tile & Concrete & Wood & \\
\hline $\begin{array}{l}\text { Disease } \\
\text { present (cases) }\end{array}$ & $29(2.25 \%)$ & $15(2.64 \%)$ & $8(1.28 \%)$ & 52 \\
\hline $\begin{array}{l}\text { Disease absent } \\
\text { (controls) }\end{array}$ & $1,261(97.75 \%)$ & $554(97.36 \%)$ & $617(98.72 \%)$ & 2,432 \\
\hline Total & 1,290 & 569 & 625 & 2,484 \\
\hline
\end{tabular}

Chi squared $=2.9861$; degrees of freedom $=2 ; P$ value $=0.2247$.

TABLE 7: Relationship between affected limb and occurrence of pectus excavatum.

\begin{tabular}{lccc}
\hline \multirow{2}{*}{ Affected limb } & \multicolumn{2}{c}{ Pectus excavatum } & \multirow{2}{*}{ Total } \\
& Present & Absent & \\
\hline Forelimb & $1(20 \%)$ & $4(80 \%)$ & 5 \\
All limbs & $7(87.5 \%)$ & $1(12.5 \%)$ & 8 \\
Hindlimb & - & $39(100 \%)$ & 39 \\
\hline Total & $8(15.38 \%)$ & $44(84.62 \%)$ & 52 \\
\hline$P<0.001$. & & &
\end{tabular}

weeks of age. Almost none of the owners recognized that the swimming movement was an abnormality. This is responsible for the delay in treatment, which leads to a reduction in the success rate of treatment. All previous reports agree that early diagnosis and treatment will result in a good prognosis, while delayed treatment results in poor prognosis.

A surprising result from this study, when comparing the 52 affected puppies, was that Golden Retrievers (15.38\%) had the highest number of puppies affected with swimming puppy syndrome, followed by Siberian Husky (13.46\%) and Labrador Retriever (9.62\%). Moreover, we also found that many medium breeds (Bulldog, French Bulldog, Crossbreed, and Thai Bangkaew) were affected by this disease. However, these figures could be explained because those medium and large breeds that were more affected by swimming puppy syndrome had a small number of average puppies per litter ( $3 \pm 1$ and $2 \pm 1$ puppies per litter for large and medium breeds, resp.). This low number of puppies per litter is a cause of overweight puppies, to the extent where puppies may not be able to stand and walk properly. However, when comparing the number of affected puppies within a breed, the highest percentage of disease was found in Bulldogs (8.33\%), French Bulldogs (7.54\%), and Pekingese (6.89\%), findings which were in agreement with previous reports $[4,5,9,12]$ where swimming puppy syndrome was commonly found in brachycephalic and chondrodystrophoid breeds.

Some clinicians have discussed the effects of the nest floor on the prevalence of this disease, but no scientific research on this issue has yet been published. In this study, tile floors produced the highest number (56\%) of cases, followed by concrete floors (29\%) and wood floors (15\%); however, there was no significant difference $(P>0.05)$ between the types of floor.

Affected limb (pathological limb) is a topic which has been widely discussed in the literature concerning this 
disease. The present results found that in $75 \%$ of cases the affected limb was predominantly a hindlimb; a lower number of cases (15.38\%) were found to have all four limbs affected; the lowest number represented cases where only the forelimb was affected (9.62\%). Together with an affected limb, pectus excavatum was found in 8 puppies: 7 puppies with all limbs affected and 1 puppy with a hindlimb affected. Only 1 puppy with all limbs affected did not show signs of pectus excavatum. Because of continuous sternal recumbency, particularly in puppies affected in the forelimb, the pressure of the body weight against the sternum causes flattening of the chest. The study data showed that an affected forelimb was significantly related to the presence of pectus excavatum. This was in agreement with previous case reports $[3-5,13,14]$, which found that all puppies with an affected forelimb also had pectus excavatum.

One disadvantage of this study is that we could not conclude that swimming puppy syndrome is one of the risk factors of pectus excavatum, because this study did not record the number of puppies affected only with pectus excavatum, without swimming puppy syndrome. A search of previous publications revealed that the prevalence of pectus excavatum in dogs has not been reported; however, in cats it was found to be $2.05 \%(5 / 244)$ [15] and in humans $1.0-1.27 \%[16,17]$. Although the present study did not primarily focus on the incidence of pectus excavatum, $0.33 \%$ of puppies ( 8 out of $2,443)$ were found to have pectus excavatum. Compared with the previous study, it seems possible that a higher percentage of cats are affected by pectus excavatum.

Swimming puppy syndrome has been considered to be uncommon, based on clinical observations and a low number of published reports. But our study indicated that a few number of puppies are affected by this disease. The primary risk factor of this disease is a lower number of puppies per litter, while other factors, including sex and floor type, may not be involved. The present results could be applied for use in future studies: for example, the possible genetic control of this disease and the potential involvement of other risk factors. Moreover, all limb lesions are associated with pectus excavatum.

\section{Acknowledgments}

The authors gratefully acknowledge the veterinarians and technician assistants in all small animal clinics and hospitals in Thailand for their kind support during the study. The authors wish to thank the National Research University Project under Thailand's Office of the Higher Education Commission for grant support.

\section{References}

[1] J. E. Harkness and L. F. McCormick, "Swimming-puppy syndrome in a litter of German Shepherd pups," Veterinary Medicine Small Animal Clinician, vol. 76, no. 6, pp. 817-821, 1981.

[2] T. W. Fossum, R. J. Boudrieau, and H. P. Hobson, "Pectus excavatum in eight dogs and six cats," Journal of the American Animal Hospital Association, vol. 25, pp. 595-605, 1989.
[3] S. C. Rahal, M. M. Morishin Filho, E. Hatschbach, V. M. V. Machado, K. P. Aptekmann, and T. P. Corrêa, "Pectus excavatum in two littermate dogs," Canadian Veterinary Journal, vol. 49, no. 9, pp. 880-884, 2008.

[4] G. Verhoeven, H. de Rooster, M. Risselada, P. Wiemer, L. Scheire, and H. van Bree, "Swimmer syndrome in a Devon rex kitten and an English bulldog puppy," Journal of Small Animal Practice, vol. 47, no. 10, pp. 615-619, 2006.

[5] C. Yardimci, A. Özak, H. O. Nisbet, and Y. S. Şirin, "Swimming syndrome in two Labrador puppies," Kafkas Universitesi Veteriner Fakultesi Dergisi, vol. 15, no. 4, pp. 637-640, 2009.

[6] V. M. Stein, M. Kohlbach, M. Fehr, and A. Tipold, "Swimmer syndrome in puppies-no indication for euthanasia!" Kleintierpraxis, vol. 52, no. 4, pp. 225-230, 2007.

[7] G. Hosgood and J. D. Hoskins, "Swimmer puppy syndrome," in Small Animal Paediatric MedicIne and Surgery, G. Hosgood and J. D. Hoskins, Eds., p. 271, Butterworth-Heinemann, Oxford, UK, 1998.

[8] J. D. Hoskins, "Swimmer puppies and kittens," in VeterInary Pediatrics, J. D. Hoskins, Ed., pp. 419-420, W.B. Saunders, Philadelphia, Pa, USA, 2001.

[9] P. F. Suter, "Swimmers flat pup syndrome," in Thoracic Radiography: A Text Atlas of Thoracic Diseases of the Dog and Cat, P. F. Suter, Ed., pp. 164-165, Wettswil, Zürich, Switzerland, 1984.

[10] D. Boettcher, R. Schmidt, C. Rehfeldt, G. Thaller, H. H. Swalve, and S. Maak, "Evaluation of MAFbx expression as a marker for congenital splay leg in piglets," Developments in Biologicals, vol. 132, pp. 301-306, 2008.

[11] S. Maak, D. Boettcher, J. Tetens et al., "Identification of candidate genes for congenital splay leg in piglets by alternative analysis of DNA microarray data," International Journal of Biological Sciences, vol. 5, no. 4, pp. 331-337, 2009.

[12] M. D. Lorenz, "The "swimming puppy" syndrome," in Current VeterInary Therapy VI: Small Animal Practice, R. W. Kirk, Ed., pp. 905-906, W. B. Saunders, Philadelphia, Pa, USA, 6th edition, 1977.

[13] S. Kongsawasdi, B. Chuatrakoon, and K. Nganvongpanit, "Physical rehabilitation treated swimming puppy syndrome," Chiang Mai Veterinary Journal, vol. 9, no. 2, pp. 105-112, 2011.

[14] R. J. Boudrieau, T. Fossum, S. M. Hartsfield, H. P. Hobso, and R. L. Rudy, "Pectus excavatum in dogs and cats," Compendium on Continuing Education for the Practicing Veterinarian, vol. 12, pp. 341-355, 1990.

[15] T. M. Charlesworth and C. P. Sturgess, "Increased incidence of thoracic wall deformities in related Bengal kittens," Journal of Feline Medicine and Surgery, vol. 14, no. 6, pp. 365-368, 2012.

[16] F. L. Westphal, L. C. de Lima, J. C. Lima Neto, A. R. Chaves, V. L. dos Santos Júnior, and B. L. C. Ferreira, "Prevalence of pectus carinatum and pectus excavatum in students in the city of Manaus, Brazil," Jornal Brasileiro de Pneumologia, vol. 35, no. 3, pp. 221-226, 2009.

[17] A. M. Williams and D. C. G. Crabbe, "Pectus deformities of the anterior chest wall," Paediatric Respiratory Reviews, vol. 4, no. 3, pp. 237-242, 2003. 

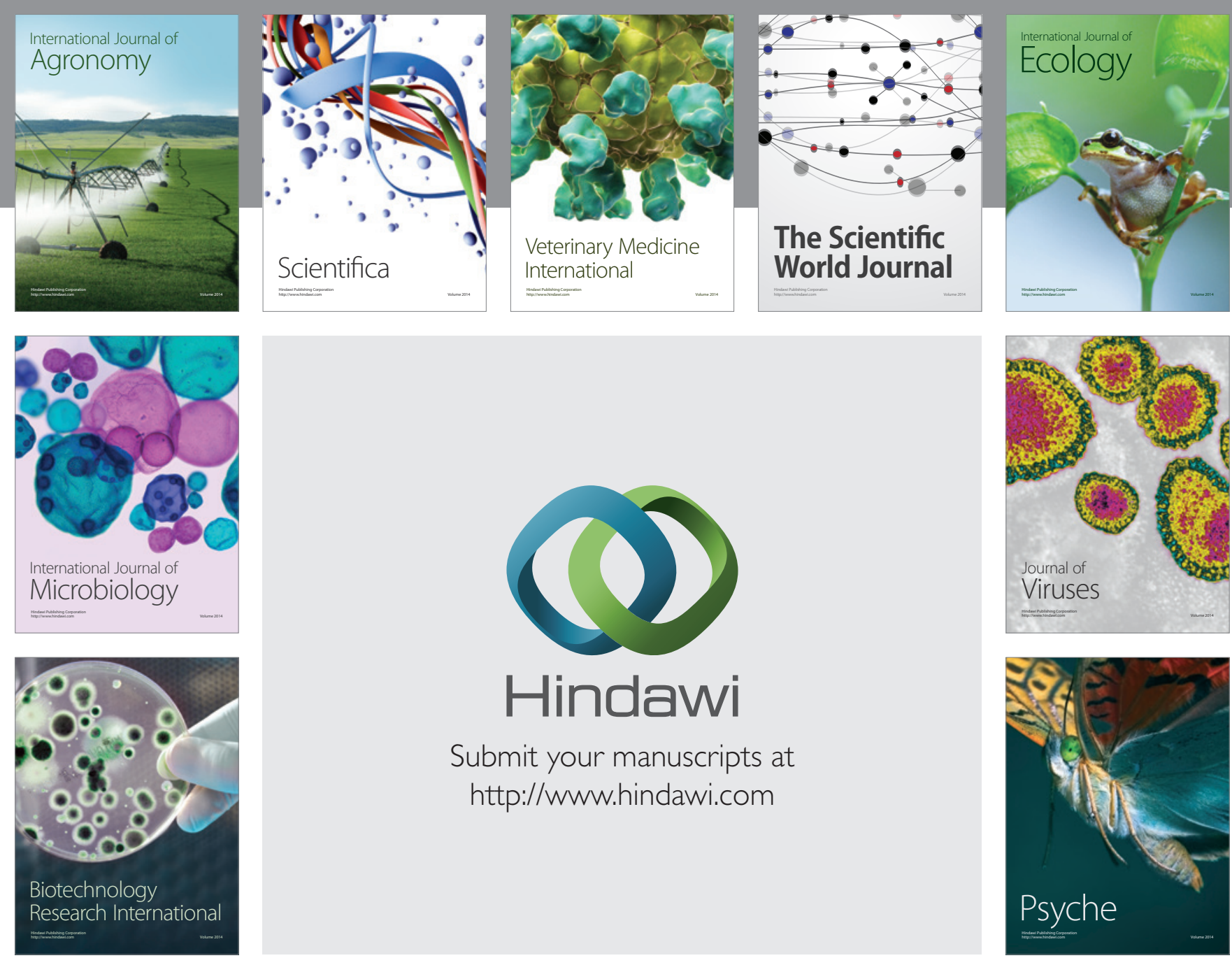

Submit your manuscripts at http://www.hindawi.com
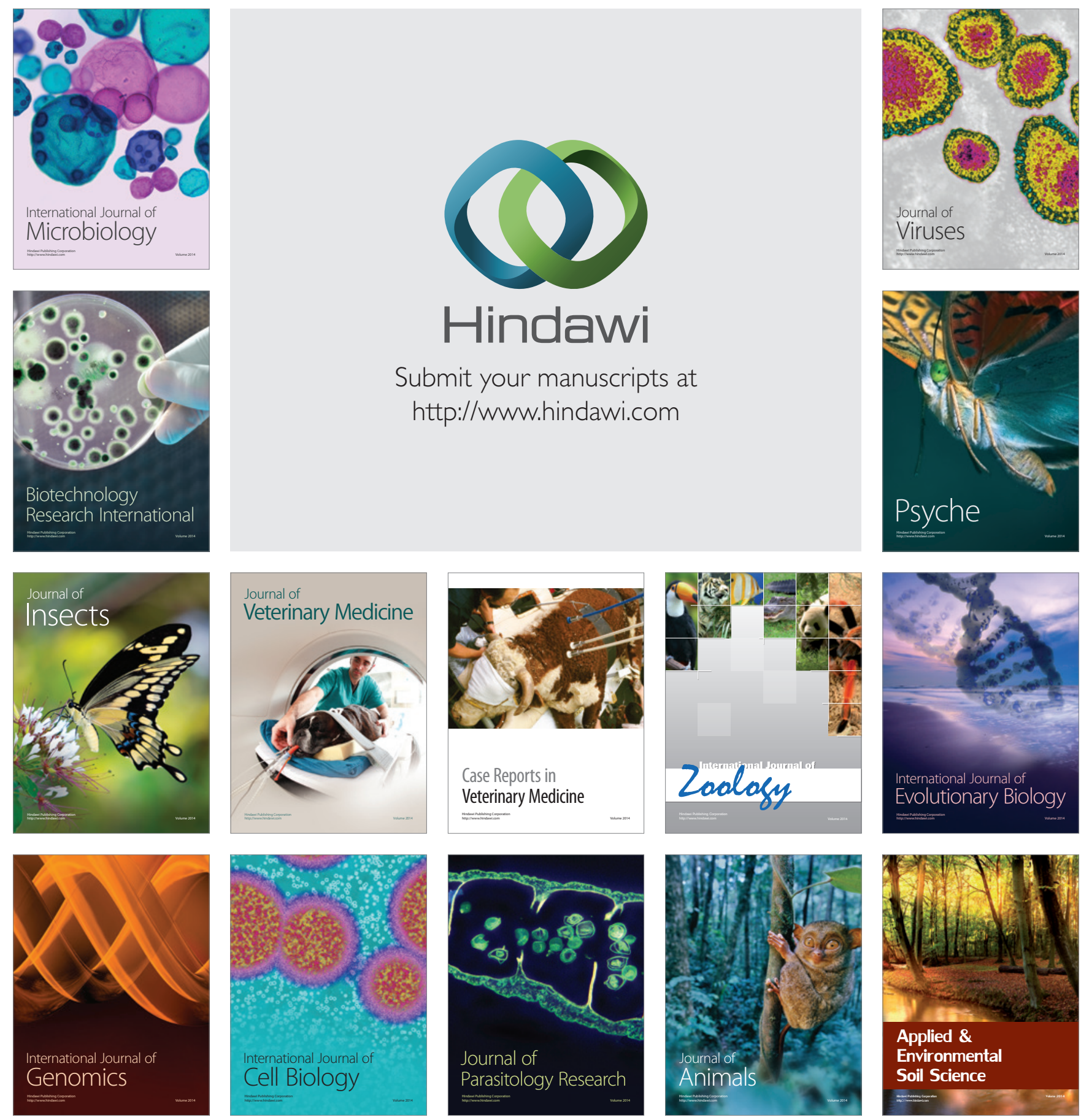